valuable information and some readers will be especially interested in the two chapters on immunity to, and serological tests for, toxoplasmosis.

All the chapters are well documented by bibliographies and diagrams and excellent photographs illustrate the text. The book, in fact, gives the reader an account, as up to date as is possible in these days of rapid advances of knowledge, of the morphological, epidemiological, biochemical and immunological factors which operate in the diseases discussed, and it will be invaluable to both the immunologist and the protozoologist and also to those who have to consider, not only the parasitic Protozoa, but also other parasitic species.

The publishers are to be congratulated on their tasteful and attractive production and good printing of a book which everyone interested in this subject should possess. G. LAPAGE

\section{DEVELOPMENTS IN GENETICS}

\section{Advances in Genetics}

Vol. 11. Edited by E. W. Caspari and J. M. Thoday. Pp. ix +394 . (New York and London: Academic Press, 1962.) $93 s$.

$7 \mathrm{HE}$ latest volume of Advances in Genetics marks a welcome return to the high standard of the early volumes in this series. It is outstanding both in the variety and in the quality of the contributions.

It is twenty years since Mather first put forward the concept of polygenic balance and discussed its relationship to natural selection. In "Linkage and Recombination in Evolution", Bodmer and Parsons provide a timely restatement of this concept supported and illustrated by the extensive data and theoretical treatments which have appeared in the meantime.

In reviewing the properties and significance of episomes Campbell achieves a fair balance between fact and speculation. From its inception the episome concept has rested on the firm basis provided by the temperate viruses. The evidence for the existence of non-viral episomes, however, remains suggestive rather than compelling. Their occurrence would presumably indicate a breakdown in cellular organization to a primitive state in which there is no distinction between chromosomal and extrachromosomal systems.

Few plant genera have attracted such a wealth of talent as the genus Enothera and as a result few have been so thoroughly investigated. In ninety pages, Cleland provides an excellent summary of the immense literature on the taxonomy, cytology, genetics, breeding systems, plastid behaviour and evolution of the North American species of Enothera.

In "Genetics and the Human Sex Ratio", Edwards examines the historical, statistical and evolutionary significance of the variation in sex ratio among families. Analyses and repeated re-analyses of the available data have produced remarkably few consistent or undisputed conclusions and one can only conclude with the author that little progress has been made in establishing the heritability of differences in the sex ratio.

To most of us, bacterial genetics means the genetics of Escherichia, Salmonella and Pneumococcus. The review by Hopwood and Sermonti of the "Genetics of Streptomyces coelicolor" directs attention to the less spectacular but steady progress that is being made with a bacterium which in morphology, at least, bridges the gap between bacteria ard fungi. Particularly interesting are the comparisons which are now possible between the genetic systems of Streptomyces and Escherichia. They have in common the incompleteness of the heterozygote at the time of their segregation, but in $E$. coli this is explained by prezygotic and in $S$. coelicolor by postzygotic loss. Streptomyces has two chromosomes, Escherichia has only one and, according to present interpretations, its structure and behaviour are intimately associated with a complex fertility system. As the genetics of Streptomyces progresses we can look forward to further illuminating comparisons.

For the final contribution we are indebted to Drs. Bulter, Sicard and Ephrussi for a translation which provides us with the first full account in English of the work of Lissouba, Mousseau, Rizet and Rossignol on the fine structure of genes in Ascobolus immersus that led to the formulation of the polaron concept. The result is not easy reading; the details are often overwhelming but the effort is on the whole worth while. It is regrettable that a comparison has not yet been possible in this mater. ial between the polaron and other units of gene structure, function and recombination.

J. L. Jinks

\section{ANATOMY OF LICHENS}

\section{Lichens}

Traité d'Anatomie Végétale. By Prof. Dr. P. Ozenda. Band VI, Teil 9. Pp. $x+199$. (Berlin-Nikolassee : Gebrüder Borntraeger, 1963.) D.M. 105; Subseription Price D.M. 84.

" $N$ the thirty-five years since the publication of the first edition of this book the spirit of lichenology has changed, so that to-day the subject of lichen anatomy needs to be viewed in a much wider context than formerly." So states Dr. Ozenda in the introduction of Lichens, Volume 6 of the Encyclopedia of Plant Anatomy. However, one reads the book with growing disappointment that the field of lichen anatomy is still so circumseribed. One longs for a mention, albeit brief, of modern work on the pure culture of the lichen components, on growth rates of lichens, and on the nature of the symbiosis.

These aspects are indeed dealt with. But although earlier work on the pure culture of the fungal and algal components and on attempted syntheses of the lichen association is reviewed adequately, the more recent work of, for example, Ahmadjian in the United States is completely omitted. A new chapter on growth has been added since the first edition, but in essence this comprises two pages, and contains no reference to recent publications. Considerably more is known about the growth rates of lichens than is implied on p. 103. A brief section deals with the physiology of the symbionts in relation to morphogenesis, but the latest work cited is for 1929, and no mention is made of the recent discussions on the possible third, bacterial, component of lichens.

Successive sections of the book deal systematically with the fungal and algal components of lichens, the vegetative anatomy, and the reproductive apparatus. The treatment is authoritative and exhaustive, and the text is lavishly illustrated with 123 figures (many of them original) and 8 plates. The illustrations are good, though often overelaborate and with details obscured by excessive shading. Printing errors oceur more frequently than is to be expected in a book of this standard - thus "constituans" in the main heading on p. 25, "Chrysotrihacées" for "Chrysothricacées" on p. 30, "Diploschistas" for Diploschistes" on Plate 3, "Pertusera" for "Pertusaria" on Plate 6, and several errors in the bibliography. In the main body of the text a number of authors ar 3 inadequately cited, and in the bibliography the abbreviations adopted for publication appear to be entirely arbitrary.

All in all, this a book for the specialist. The price alone places it beyond the reach of most botanists, while the subject-matter is of direct appeal to only a few dedicated lichenologists. As a reference work within a very limited field this book is invaluable, but for the nonspecialist reader seeking a general account of lichen structure the corpus of facts may prove intimidatory, and the lack of references to modern experimental work a serious deficiency. 